\title{
Interactive comment on "A complex aerosol transport event over Europe during the 2017 Storm Ophelia in CAMS forecast systems: analysis and evaluation" by Dimitris Akritidis et al.
}

Dimitris Akritidis et al.

dakritid@geo.auth.gr

Received and published: 18 September 2020

The comment was uploaded in the form of a supplement:

https://acp.copernicus.org/preprints/acp-2020-467/acp-2020-467-AC3-supplement.pdf

Interactive comment on Atmos. Chem. Phys. Discuss., https://doi.org/10.5194/acp-2020-467, 2020. 